\title{
Effects of Utilization of Maternal Health Care Services on Child Spac- ing: A Study from Eastern Nepal
}

\author{
Ishwari Sharma Paudel ${ }^{1}$, Rabin Gautam ${ }^{1}$ \\ ${ }^{1}$ School of Public Health and Community Medicine, B. P. Koirala Institute of Health Sciences, Nepal
}

\section{Correspondence \\ Dr. I. S. Paudel \\ Additional Professor, School of \\ Public Health and Community \\ Medicine, B. P. Koirala Institute of \\ Health Sciences, Dharan, Nepal \\ E-mail: is_paudel@yahoo.com}

DOI: http://dx.doi.org/10.3126/

jemsn.v10i4.12973

\begin{abstract}
Objective: This study was conducted to explore the effect of utilization of Antenatal Care Service on subsequent birth interval. Methods: A cross-sectional study was conducted among 517 women giving birth during five years period preceding survey. The Cox proportional hazard model was used to analyze birth interval as a multivariate life table model. Results: ANC utilization was higher among mothers living in mountain, Indo-Aryan high caste and mothers having more than 10 years of schooling. Regression analysis showed that being TibetoMongoloid caste, mothers with female index child and mother with dead index child had higher risk of having next birth. Conclusion: There is a strong positive relationship between the utilization of ANC service and less risk of child bearing. $(\mathrm{RR}=1.873, p=0.008)$

Keywords: ANC Services; Birth Interval; Proportional Hazard Model; Contraception; Health Institution; Nepal
\end{abstract}

Citation: Paudel IS, Gautam R. Effects of utilization of maternal health care services in child spacing. JCMS Nepal 2014;10(4):22-5.

\section{INTRODUCTION}

Family planning is regarded as an important component of the maternal and child health care. The provision of maternal and child health care services is said to be an important motivation force for couples to adopt family planning methods. Antenatal care services provide a bridge for the women to the health care delivery system. ${ }^{1}$

Despite the integration of the family planning in the ANC services, much is not known about ANC services playing role in the child spacing. Surprisingly, only limited research have been carried out to show the role of ANC services with family planning. The result seems mixed in various studies. And whether the ANC services will lead to family planning use or both of these are related to some other factors is not clear.

Kumar and Srinivasan ${ }^{2}$ showed that the rate of acceptance of permanent family planning method (sterilization) among those who received maternal and child health care remains high even among those couples who reside in a distant village from the health care centers.

The use of ANC services motivates pregnant women to have delivery in hospital or at home attended by health professionals. Utilization of ANC services helps in generating a salutary effect on the acceptance of the family planning methods ${ }^{3}$. Not only the contraceptive prevalence is found to be higher among the ANC users, but also they are more inclined towards using contraception in future and are more likely to adhere to small family norm. Promotion of spacing method among women who come for ANC at health facility is easier.

Similarly other studies ${ }^{4,5}$ reported a strong usage of ANC use and subsequent family planning services. 
Similarly in Morocco, Guatemala and Indonesia, use of $\mathrm{MCH}$ service provided the gateway to the family planning use. ${ }^{6}$

Nepal in the Eastern Development Region accommodates $23.1 \%$ of the total population of the country. ${ }^{7}$ Total fertility rate (TFR) is 3.8 children per women which was slightly low as compared to country's TFR (4.1). ${ }^{8}$

The aim of this study is to explore the effect of the utilization of antenatal care services as an indicator of contraceptive use and fertility by taking the most recent birth interval as the outcome variable in Eastern Region of Nepal.

\section{MATERIALS AND METHODS \\ Data}

Topographically Nepal is divided into three different regions- Mountain, Hill and Terai. Data for the present study were taken from three Village Development Committees (VDCs), each of which were from three different regions namely Mountain, Hill and Terai. Information about the utilization of health care services was only taken to the last live born child (alive or dead at the time of survey) to minimize recall laps.

\section{Outcome}

The main outcome study variable is the length of the most recent birth interval and the interval between last and next-to-last birth before the survey. Censored observations are taken as the interval between the date of birth of last child and the survey date for those women with one birth in the last five years prior to survey. Birth intervals more than 60 months are considered as 60 months and they are also kept in the category of censored observations.

\section{Independent}

The main independent variable of interest is the use of ANC services relating to the last child birth within five years before the delivery. Sociodemographic variables taken for the study were age, sex of the index child, survival status of index child, caste of the women, religion, gender and current age of the women. Variables related to the maternal health care services were ANC (for the index child), place of delivery and attendance of health workers during delivery.

\section{Statistical tool}

The Cox proportional hazard model was used to analyze the birth interval as a multivariate life table model $^{9}$.

\section{RESULTS}

Table 1 shows the distribution of utilization of ANC service and use of family planning methods with background characteristics among mothers who had live births in the last five years preceding the survey. The utilization of ANC services was found to be higher in Mountain followed by Hills than in Terai, whereas use of family planning methods was almost same in Mountain and Terai.

Table 1: Table 1: Distribution of utilization of ANC and current use of family planning methods in mothers with live birth baby with various background variables

\begin{tabular}{|l|l|l|l|l|}
\hline \multicolumn{2}{|c|}{ Characteristics } & $\begin{array}{l}\text { No. of } \\
\text { Women }\end{array}$ & $\begin{array}{l}\text { A N C } \\
\text { R e } \\
\text { ceived } \\
(\%)\end{array}$ & $\begin{array}{l}\text { C u r - } \\
\text { rent use } \\
(\%)\end{array}$ \\
\hline \multirow{4}{*}{ Residence } & Terai & 296 & 76.9 & 60.3 \\
\cline { 2 - 5 } & Hill & 161 & 82.6 & 37.3 \\
\cline { 2 - 5 } & Mountain & 60 & 91.7 & 62.0 \\
\hline \multirow{3}{*}{ Religion } & Hindu & 376 & 80.2 & 58.5 \\
\cline { 2 - 5 } & Others & 141 & 81.4 & 38.9 \\
\hline \multirow{4}{*}{ Caste } & Indo-Aryan High & 137 & 88.1 & 62.5 \\
\cline { 2 - 5 } & Indo-Aryan Low & 156 & 80.8 & 52.9 \\
\cline { 2 - 5 } & Tibeto-Mongoloid & 149 & 83.3 & 39.6 \\
\cline { 2 - 5 } & Terai Indigenous & 75 & 58.6 & 62.7 \\
\hline \multirow{4}{*}{ Education } & No. of Schooling & 349 & 75.8 & 54.9 \\
\cline { 2 - 5 } & $\mathbf{1 - 5}$ Years & 58 & 89.8 & 38.1 \\
\cline { 2 - 5 } & 6-10 Years & 51 & 81.3 & 47.5 \\
\cline { 2 - 5 } & $\mathbf{1 0}$ Years & 59 & 95.0 & 58.4 \\
\hline \multicolumn{2}{|c|}{ Total } & $\mathbf{5 1 7}$ & $\mathbf{8 0 . 6}$ & $\mathbf{5 2 . 1}$ \\
\hline
\end{tabular}

As shown in table 1, Hindus were more in the study sample, non-Hindu mothers appear to be utilizing ANC services slightly more. But the use of family planning methods was found to be low in nonHindu group as compared to Hindu group. Utilization of ANC services was quite low in Terai 
Indigenous caste group but the figure was almost same in other three caste group. Use of family planning method was very low in Tibeto-Mongoloid followed by Indo-Aryan-low and Indo-Aryan-high and Terai Indigenous caste group.

Table 2: Estimated regression coefficient from proportional hazard model based on last birth interval

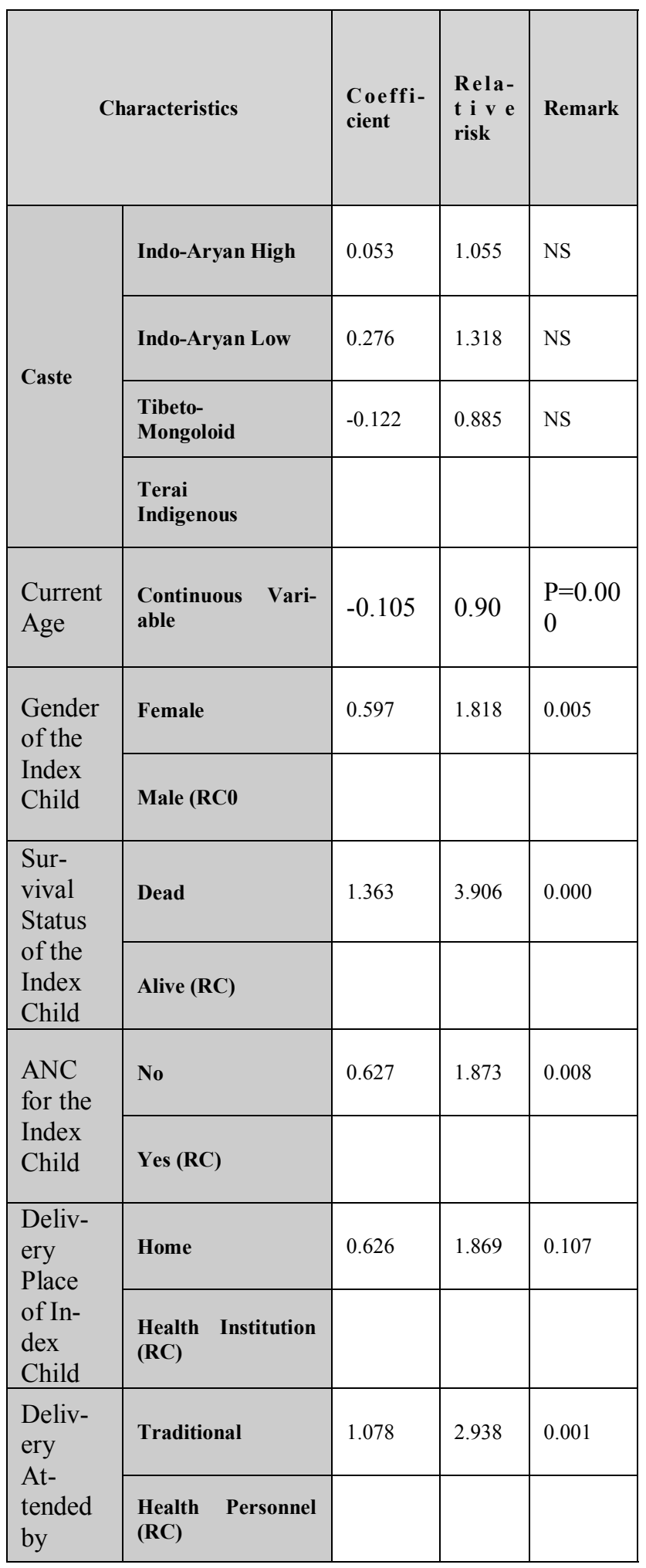

The utilization of ANC service and the use of family planning methods were higher among literate especially with those who completed 10 years of schooling as compared to less educated women.

Table 2 represents estimated regression coefficient and relative risk to experience next birth by selected socio-demographic factors and health care service indicators. Only those variables significant at 0.20 levels were included in the final multivariate analysis. Tibeto-Mongoloid caste group have relatively lower risk of experiencing next birth and IndoAryan-High and Indian- Aryan -Low caste group have higher risk of experiencing next birth as compared to Terai - Indigenous caste group. Despite this, they were not found to be statistically significant.

Mothers with a female index child had more risk of giving birth than the mothers with male index child. Mothers whose index child was dead would almost invariably give birth to a child than those mothers whose index child was alive. Women who utilized ANC services had significantly less risk of childbearing as compared to those who did not utilize ANC services. The utilization of antenatal care service was found to be an important factor in determining the timing of next birth, which confirmed the interrelationship of the utilization of ANC service and the use of contraception.

\section{DISCUSSION}

This study reveals that the effect of positive attitude and behavioral change in health care services to the length of birth interval. It showed that there is a strong positive relationship between the utilization of antenatal service and the length of the birth interval. The use of ANC service motivates pregnant women to have delivery in hospital/ health institution or at the home attended by health professionals. ${ }^{10}$ Treating ANC utilization as a bridge for contraceptive environment, we found that the difference in the length of birth interval. It is possibly due to the confounding effect of the place of delivery and attendance by health professionals during the 
delivery. It may be due to that majority of the users are using contraceptives for limiting births rather than for spacing especially in their open birth interval. Counseling and follow up activities should be undertaken to promote the use of spacing method in addition to the permanent method. ANC utilization provides an atmosphere and level of motivation to women toward meeting their health needs. This further reinforces to go for institution deliveries and antenatal care services, where they are motivated to use contraceptives for spacing at younger ages. ${ }^{11} \mathrm{In}$ Nepal, most of the contraceptive users have been found to be older in age (crossed 35 years) and higher parity having four/five children. ${ }^{8}$ Hence, there is a need to motivate to utilize health facilities which helps to create favorable condition to space between births and limit the number of children. and the use of contraception.

\section{CONCLUSION}

This study showed that there is a strong positive relationship between the utilization of antenatal service and the length of the birth interval. The use of ANC service motivates pregnant women to have delivery in hospital/ health institution or at the home attended by health professionals create contraceptive environment and increase the length of birth interval. ANC utilization provides an atmosphere and level of motivation which further reinforces to go for institution deliveries and antenatal care services, where they are motivated to use contraceptives for spacing at younger ages. Further, health care utilization should be emphasized in the educational program and enhance community involvement as well to persuade women to use health facilities which helps to create favorable contraceptive environment.

\section{REFERENCES}

1. Do M, Hotchkiss D. Relationships between antenatal and postnatal care and post-partum modern contraceptive use: evidence from population surveys in Kenya and Zambia. BMC Health Services Research 2013;13(6):6. DOI: 10.1186/1472-6963-13-6. PMid:23289547.

2. Kumar R. Integration of family planning with health services-A preliminary study. Indian Journal of Medical Res- -earch 1974; 62(5): 800-6. PMid:4435892.

3. Pandey A, Mishra P, Ojha A. An Analysis of the child Spacing Effect of the Utilization of Maternal Health Care Services in Some Selected States of India. Biostatics Aspects of Health and Epidemiology. ed Pandey CM, 2002: 39-46.

4. Yadav D, Dhillon P. Assessing the Impact of Family Planning Advice on Unmet Need and Contraceptive Use among Currently Married Women in Uttar Pradesh, India. PLoS ONE 2015;10(3):e0118584. DOI: 10.1371/ journal.pone.0118584.

5. Zerai A, Tsui AO. "The relationship between prenatal care and subsequent modern contraceptive use in Bolivia, Egypt and Thailand." African Journal of Reproductive Health 2001;5(2):68-82. DOI: $10.2307 / 3583432$. PMid:12471915.

6. Hotchkiss RD, Rous JJ, Seiber EE, et al. "Is maternal and child health service use a causal gateway to subsequent contraceptive use?: A multi-country study." Population Research and Policy Review 2005;24(6)543-71. DOI: 10.1007/s11113-005-4852-0.

7. Central Bureau of Statistics (CBS), 2003. Population Monograph of Nepal Vol (1) and (2) (Kathmandu: CBS).

8. Ministry of Health and Population: Nepal Demographic and Health Survey Main report. Family Health Division. Kathmandu: HMG, MOHP;2001.

9. COX D.R. Regression model and life table. Journal of Royal Statistical Society,1972;34:184-220.

10. Acharya LB. "Utilization of Antenatal Care Services in Rural Areas of Western and Mid-Western Hills of Nepal". Ed Kumar B, Population and Development in Nepal 2000;7:111-22.

11. Nath DC, Singh KK, Talukdar PK. "Most Resent Birth Intervals in a Traditional Society: A Life Table and Hazards Regression Analysis. Canadian studies in population 1994;21(2):149-64. 